\title{
ANIMA' RI CHO, ANIMA' RI PLO: \\ ESPÍRITU DE LA LAGUNA, ESPÍRITU DEL MAR. ACERCA DEL DÍA IMOX ENTRE LOS K'ICHE'
}

\author{
Canek Estrada Peña \\ Posgrado en Estudios Mesoamericanos, \\ Universidad Nacional Autónoma de México
}

\begin{abstract}
Resumen: Por medio del análisis de información etnográfica y etnohistórica acerca del día denominado Imox (equivalente al Imix del sistema maya yucateco), uno de los 20 nawales (días de la cuenta de 260 días usada por los k’iche' y otras comunidades linguiísticas mayas del altiplano guatemalteco), el artículo reflexiona sobre los procesos semióticos por los que los símbolos y significados del pasado llegan a la vida contemporánea de los mayas de hoy, y en qué modo la memoria y la creación de nuevos sentidos juegan un papel de primer orden en el entendimiento que tienen de su cultura. Más allá de cuestionar qué tan original es o no el significado contemporáneo del día, el texto se detiene en los posibles motivos de las transformaciones que ha sufrido, de los que dan fe diversas fuentes.
\end{abstract}

Palabras clave: Cholq’ij, mayas k'iche', nawal-día, entidad del agua, semiosfera.

AвSTRACT: This article analyzes, through the collection and analysis of ethnographic and ethnohistorical information, one of the twenty nawales account of 260 days used by the K'iche' and other Mayan linguistic communities of the Guatemalan highlands - the day called Imox (equivalent to Imix in the Yucatec system). It reflects a semiotic processes by which the symbols and meanings of the past come to the contemporary Maya life today, and how memory and creation of new senses play a major role in the understanding they have of their culture. To do this, it is not so important the question of what was or was not the original meaning of the day, focusing instead on the possible reasons for the changes it has undergone as we have foundd in various sources.

KeYwords: Cholq'ij, Maya K'iche', Nawal-day, water entity, semiosphere.

RECEPCIÓN: 14 de febrero de 2014.

ACEPTACIÓN: 29 de mayo de 2014. 



\title{
ANIMA' RI CHO, ANIMA' RI PLO: \\ ESPÍRITU DE LA LAGUNA, \\ ESPÍRITU DEL MAR. \\ ACERCA DEL DÍA IMOX ENTRE LOS K'ICHE'
}

\author{
Canek Estrada Peña \\ Posgrado en Estudios Mesoamericanos, \\ Universidad Nacional Autónoma de México
}

Qué cosas tiene el mar, está loco, una noche en el infierno y al amanecer como un plato, tranquilo, tranquilo...

José Emilio Pacheco Cuando salí de la Habana, Válgame Dios

Los diferentes grupos mayas que habitan los Altos de Guatemala son depositarios de una de las tradiciones calendáricas más singulares de Mesoamérica, ya que, en la actualidad y de manera ininterrumpida desde la época prehispánica, llevan día con día la cuenta calendárica de 260 días. Este sistema sígnico-cronológico recibe el nombre entre los k'iche' de Cholq'ij, que literalmente quiere decir "orden” o "acomodo de los días". ${ }^{1}$ Este sistema fue un elemento cultural usado en la época prehispánica en buena parte del área mesoamericana y por gente de diversas lenguas, que, sin embargo, compartían dicha cuenta sin mayores modificaciones; entre los nahuas del centro de México se le conoció como Tonalpohualli, y entre los zapotecos como Pije, por citar algunos ejemplos. Para referirse a este sistema en la cultura maya se ha adoptado el término de Tzolk'in, propuesto en 1921 por William Gates (Thompson, 1960: 97; Tedlock, 2002: 222).

El sistema funciona básicamente asignando a cada día un nombre compuesto por un elemento natural o cultural —entre los que podemos encontrar animales, plantas, fenómenos naturales, herramientas, personajes mitológicos o conceptos abstractos- asignados con base en una serie estandarizada y secuencial de 20 nombres propios, los cuales se repiten cuando termina de pasar cada uno de ellos de manera invariable e ininterrumpida. Dicho nombre se combina con un numeral —del uno al 13-, en otra serie paralela, también invariable. Así 20 nombres combinados con 13 numerales dan por resultado el ciclo completo de 260 días, ya que este número representa el mínimo común múltiplo entre las dos cifras ante-

\footnotetext{
${ }^{1}$ Proviene de los vocablos chol, "alinear”, “ordenar”, y q’ij, “día”, “sol”.
} 
riores. Los nombres propios de los días expresados en k'iche' son los siguientes: B’atz', E, Aj, I’x, Tz’ikin, Ajmaq, No’j, Tijax, Kawuq, Ajpu, Imox, Iq', Aq'ab’al, K’at, Kan, Kame, Kej, Q'anil, Toj y Tz’i. ${ }^{2}$

En esta ocasión, el análisis que pretendo abordar gira en torno a los significados atribuidos a uno de estos 20 nombres de los días del Cholq’ij, denominado Imox en la oralidad contemporánea.

\section{Etnografías en las comunidades k'iche'}

Presentaré aquí una selección de textos escritos acerca del día Imox, obedeciendo a un criterio diferencial respecto al origen de los autores, debido a que las motivaciones y el contexto en el que escribieron son diferentes. En un primer lugar están aquellas referencias de etnógrafos provenientes de la cultura occidental; en segundo, las que fueron escritas por autores mayas. Desde la primera mitad de siglo xx existió una intensa actividad etnográfica en varias comunidades guatemaltecas, a resulta de lo cual se producen valiosas monografías. Debido al espacio y el fin de este artículo no puedo detenerme en una valoración más justa de los diferentes autores que describieron el uso ritual de este sistema calendárico, así que sólo me serviré de lo que dijeron respecto al tema que me atañe.

Leonhard Schultze Jena investigó acerca del calendario indígena sobre todo en las comunidades de Momostenango y Chichicastenango a principio de la década de los años treinta del siglo xx. Sobre el día Imox escribió:

Imóx, imúx (no mo’x - loco) - Día malo. En Momostenango rezan en dicho día para que le sobrevenga un castigo a quien haya causado mal a alguien. Ya no se conoce en ese pueblo el significado de imox, y en Chichicastenango le dan el significado de mo'x, aunque se pronuncie la palabra correctamente. Estiman que este día sea eficaz para las rogativas en pro de los pobres de espíritu, y en general es el día de los zurdos, o sea de lo que es alrevesado, de lo que está embrollado, de lo que causa pleitos. Esta creencia popular parecería justificar la etimología vulgar de dicha palabra. Sin embargo; hay que tomar en cuenta que puede ser muy posible que dicha interpretación pueda haber originado posteriormente al uso de este vocablo. Este problema puede resolverse únicamente pronunciando imóx correctamente por boca y para el oído del aborigen, y no con ciertos extravíos fonéticos que conducen a toda clase de supuestos.

Aunque el sentido esencial de este día es considerado como "malo" puede ser que una oración dicha en ese día con el propósito de contrarrestar algún mal, tenga éxito. Así, por ejemplo, en los días imóx se hacen ofrendas en la montaña con el fin de obtener una reconciliación, cuando ha habido disgustos conyugales (SchultzeJena, 1946: 36).

\footnotetext{
${ }^{2}$ Aunque por lo regular los nombres son listados comenzando por Imix (equivalente de Imox), yo me apego a la manera empleada en la actualidad entre los mayas del altiplano guatemalteco, que de manera casi estandarizada comienzan por B'atz' (Estrada, 2013: 231-232).
} 
En las mismas épocas, Ruth Bunzel también hizo trabajo etnográfico en Chichicastenango. Consignó:

Imux (cosa oculta). Símbolo de las fuerzas ocultas en el universo, manifestadas en demencia. Imux es el nombre de todas las cosas secretas u ocultas. En general es un día malo, un día peligroso. Pero si uno no tiene malos pensamientos y si la personalidad de uno es abierta y sincera, entonces no es un día malo, sino un día de esperanza.

Si las adivinaciones salen en 7 ajpú, 8 imux, 9 iq', es un asunto de omisión o confusión con respecto a los ídolos en la casa de uno. Uno no pudo haber dado gracias, o uno pudo haber peleado en presencia de los ídolos (Bunzel, 1981: 334).

Más adelante, durante los años sesenta, Bárbara Tedlock amplió considerablemente el conocimiento acerca del significado y el uso de los días en Momostenango. Comenta sobre el día que nos interesa:

Las nemónicas ${ }^{3}$ para Imöx son kamöxirik, "se posesiona o se vuelve loco", nimalaj k'ulel, "gran enemigo", y kumatz rib' chikiwach Mam, "humillarse ante el Mam”.

Los días 1, 6, y 8 Imöx, un ajq'ij visita los altares públicos apropiados, donde se humilla (kumatz rib') ante los Mam (Kej, E, No’j, Iq') para que no sea dominado por su poder; que lo vuelve loco (kamöxirik). [En] los días Imöx con números altos, los ajq'ij poderosos van a los altares en las cimas de las montañas para presentarse ante los Mam, pidiéndoles que dominen a las personas que han usado la brujería contra otros. Esta dominación llega en forma de una enfermedad con un componente mental y uno físico. El contador del tiempo que llama directamente al poder de los Mam para perjudicar a otros de esta manera es el gran enemigo (nimalaj k'ulel) que trae el castigo divino sobre sus enemigos. Ésta se considera una práctica muy peligrosa, porque los Mam, después de oír el caso, podrían decidir dominar a la persona que hizo la petición en vez de la víctima destinada. Los nueve o trece días consecutivos de las dos ceremonias principales de brujería siempre incluyen un día Imöx para avisar a los Mames de la víctima futura.

En la cuenta del tiempo con respecto a una enfermedad, Imöx indica que un enemigo ( $k^{\prime} u l e l$ ) ha pedido la enfermedad; entre más bajo el número, menos seria va a ser la enfermedad. Cuando es uno de los primeros resultados en una cuenta del tiempo con respecto a un matrimonio, Imöx significa que la mujer deseada podría enloquecer (kamoxirik) al cliente; mediante su infidelidad u otras acciones maléficas, dominaría al hombre. Al presagiar para un viaje o un trato comercial, Imöx indica tantos problemas y tanta complejidad que uno se volvería loco.

Un niño nacido un día Imöx será dominado por el poder de los Mam. Como resultado, será débil, ineficiente, desorientado, aun loco. Aunque tal persona no puede efectivamente entrenarse como contador del tiempo, se interesará bastante

${ }^{3}$ Esta autora señala que mucho del sentido contenido en cada uno de los días se da a partir no de la etimología del nombre del día, sino por una serie de frases nemónicas "que combinan los significados de los días de acuerdo con las acciones sociales que los caracterizan. Estas frases frecuentemente incluyen los sonidos del nombre del día pero no necesariamente incluyen el nombre mismo" (Tedlock, 2002: 109-110). 
en la brujería y tal vez compre de los vendedores ambulantes que venden oraciones impresas a San Simón y a otros santos malos, publicados en México, Honduras, y en Mazatenango, Guatemala. Se dice que la gente que depende únicamente de materiales impresos para tratar de llevar a cabo tales actos peligrosos se vuelve loca (Tedlock, 2002: 109-110).

En los años noventa, Walburga Rupflin recopiló esta información de un ajq’ij k'iche', aunque no indica su procedencia

El significado de Imox es que en la familia de repente crece un lío. El Imox es el disgusto, es el pleito, que nace en la propia familia.

Y el niño que nace en el Imox es un niño muy llevado, no es fijo. Estas personas dudan mucho y son indecisos, tienden a desequilibrios materiales y espirituales. Estos problemas son prevenibles.

En las ceremonias de Imox se pide rechazar las malas ideas, Imox es las malas ideas, moxrik, tontirik, se dice en k'iche', rechazar las malas ideas, y pleito en la familia, en la propia familia o afuera, eso es el Imox (Rupflin, 1999: 106).

A partir de la década de los noventa cobró fuerza la "Espiritualidad Maya" en Guatemala, la cual podemos definir como una arista del movimiento maya surgido a partir de la segunda mitad del siglo xx. Los integrantes del movimiento afines a esta ala espiritual promulgan "una cosmovisión propia consistente en la relación armónica con la naturaleza y el universo, una forma de concebir y contar el tiempo que se concretiza en el uso del calendario maya" (Bastos et al., 2007: 8); así también cuestionan la historia oficial que durante años ha postulado la discontinuidad entre los antiguos mayas y los "indígenas" actuales, afirmando que los pueblos mayas de hoy son descendientes directos de los mayas de la época precolonial. Con base en estas premisas, la reivindicación de la identidad étnica se convierte en una manera de plantear la continuidad de la cultura como una forma de resistencia, y dentro de ésta, las creencias cosmogónicas y religiosas de las diferentes comunidades linguiísticas mayas se constituyeron en un componente importante del activismo por los derechos culturales. Su mayor presencia pública se dio después de la firma de paz y el fin oficial de la guerra civil, pues ello permitió el surgimiento de organizaciones indígenas dedicadas de lleno a la práctica de las ceremonias mayas, la defensa de los lugares sagrados y la promoción del uso del Cholq'ij (Cojtí, 1997: 108; Esquit, 2002: 12; Morales, 2004: 44-45).

Dentro de este contexto surge una gran cantidad de literatura escrita por autores mayas pertenecientes a este movimiento, que pretende dar a conocer el significado y uso del calendario sagrado de 260 días. De estas obras he seleccionado algunos ejemplos interesantes que describen los 20 nawales de los días, y en los que podemos leer varios significados atribuidos a Imox ausentes en los trabajos etnográficos anteriores. La comparación entre ambos tipos de fuentes nos será útil en la discusión final. 
Imox: Es la otra parte de la fuerza no desarrollada. El segundo cerebro. Etimológicamente Imox significa: izquierdo. Movimiento brusco o constante.

Imox equivale a lagarto, o sea el nawal de las aguas. Representa las fuerzas naturales invisibles, positivas y negativas. Es el nombre de todas las cosas ocultas o secretas.

Imox es un día delicado. Debe mantener el equilibrio, porque sus acciones pueden ser positivas como también negativas. Es un día especial para pedir lluvia y la solución de los problemas familiares (Yool y Curruchich, 1999: 13).

Imox: Significa locura.

Nawal del agua, mares, lagos y ríos. Nawal de la lluvia y de los animales acuáticos.

Es un buen día para pedir lluvia, es un día para pedir la inteligencia para contrarrestar lo indebido. Este día puede ser variable para las reacciones humanas, por lo tanto, si la persona no se cuida puede variar de carácter extremadamente.

Es un buen día para tratar los trastornos mentales, para encontrar el camino apropiado ante las dificultades de la vida.

Las personas nacidas en él son inteligentes, muy trabajadoras, pero son de carácter variable. La persona nacida en Imox debe ofrendar cada 20 días para que su vida resulte siempre bien y buena.

No nos olvidemos del Imox cuando hay sequía, pues este día es el sustentador de la vida al darnos agua en abundancia para que la creación florezca y se reproduzca (ALMG, 2001: 52)

Imox: Significa locura, lagarto y pez.

Es el Nawal del mar, ríos y lagos, día para sanar enfermedades de la mente, para agradecer y pedir la lluvia.

Las cargas de este Nawal son:

Positivo: buen ayudante, tiene presentimientos, psicólogo.

Negativo: enfermedades de la mente, olvidadizo, destructor (Guorón et al., 2002: 77).

Imox: Es el nawal de trasgresión de los principios, normas y valores en la convivencia en su forma negativa o positiva. Es el nawal del desequilibrio físico, psicológico. Es el nawal cuidador de la casa, del mar y de las grandes heladas. La persona Imox es manifestador de gran respeto ante la naturaleza. Mediador entre los cargadores del tiempo. Puede ser educado como Ajq'ij.

Significa: su animal el pez. Desequilibrio. Es el nawal del Mar, indicado para sanar enfermedades mentales.

\section{Características:}

Positivo:

- Producir, creativo, artista, médico, trabajador

- Pensador, captores de los mensajes cósmicos.

- Su trabajo es cooperar

- Tiene habilidad y facilidad en hacer cualquier tipo de trabajo manual.

Negativo:

- Inseguro, violentado, alocado, sin control, agresivo, indeciso, tambalea, desordenado, desconfiado, necio, lento (CONIC, 2002: 21). 
Imox: Representa la sabiduría, el futuro. Los nacidos bajo este Nawal son videntes, curanderos, jala hueso y manejan e interpretan la piedra de cuarzo.

Representa la blancura y la pureza.

En este día se puede pedir que nuestras manos se llenen de energía para poder curar y sanar a los enfermos.

Negativo: son alocados, trastornados, son codiciados, no son responsables (Asociación Ixoq Ajaaw, 2003: 36)

Imox: Significa idiotez, locura. Imosh es todo lo que corresponde al lado izquierdo en lo negativo.

Día especial para:

- Pedirle que regrese una mujer que ha abandonado a su esposo.

- Pedir que regrese un hombre que ha abandonado a su esposa.

- Pedirle para que regrese una persona que ha abandonado a su familia o a su país.

- Pedirle que llueva, al Nahual del Mar (Cucumatz), al Nahual del río, y del lago (Peteu).

- Pedirle que calme los trastornos mentales.

- Pedirle que calme los trastornos espirituales.

- Pedirle que calme los temporales.

- Pedirle que calme las locuras en el hogar (Ixcot Pérez, 2004: s. p.).

Imox. Significado: Agua, mar, intranquilidad, locura, pleito, producción, cerebro

Color: Amarillo, verde, celeste

Interpretación: símbolo de las fuerzas ocultas en el universo, manifestadas en demencia. Día cuando las fuerzas de la naturaleza se tornaron peligrosas; a la vez es un día que propone orden como equilibrio del desorden.

Imox es el nombre de todas las cosas ocultas o secretas. Representa también el lado izquierdo, brazo izquierdo cuya misión es ayudar al brazo derecho a realizar una cooperación eficaz con el Corazón del Cielo. Corazón de la Tierra en el desenvolvimiento del mundo y de la humanidad.

Características: La persona nacida ante el día Imox fue engendrada en el día Aj y su destino será regido por día Toj. Le será necesario consultar con el Ajq’ij —quién sabe buscar el equilibrio - para superar las energías negativas y ser alguien con una personalidad abierta y sincera. Su día no le acarreará dificultades sino será un día lleno de esperanza. Puede llegar a ser Ajq'ij.

Características positivas: Productor, creativo, artista, trabajador, gran pensador, con habilidad y facilidad en hacer manualidades.

Características negativas: Inseguro, violento, indeciso, desordenado, desconfiado, necio, lento.

Características médicas: Su salud está determinada por alteraciones de su temperamento, sin control, inestable, lleno de incertidumbre por no saber qué hacer ni qué buscar. Puede llegar a la locura y a perder el juicio de la razón.

Aplicación: las ceremonias que se realizan sirven para ayudar a las personas con cargas negativas, también para lograr curaciones y ofrendar ante la Madre Tierra.

Día propicio para la lluvia, para que se mantengan vivos los ríos, que no se sequen los pozos y las lagunas (CCAM, 2005: s. p.). 


\section{Trabajo de campo: El nawal ${ }^{4}$ del agua}

En los siguientes tres apartados presento un resumen de lo que he podido documentar en diversos pueblos del territorio k'iche' durante mis propias estancias en Guatemala, del 2009 al 2012. En el desarrollo de esta investigación, todos los guías espirituales $\left(a j q^{\prime} i j a b^{3}\right)^{5}$ que logré consultar coincidieron en señalar al nawal Imox como dueño, guardián o energía del agua. Algunos se refieren a él como anima" ri cho, anima' ri plo; "espíritu de la laguna, espíritu del mar" como una manera de indicar que es la fuerza que anima a todas las formas posibles en que el agua se manifiesta.

Al nawal Imox es a quien se ruega para que haya abundancia de lluvia y no sobrevenga la sequía. También se le invoca en aquellos lugares donde la gente se abastece de agua para su consumo personal, los cuales pueden ser manantiales, ríos, lagos o incluso cajas de agua de concreto. Para indicar la sacralidad de estos sitios, es común encontrar cruces de madera adornadas con flores o con hojas de ch'ayuj (Dracaena Draco) (figura 1). En estos casos la cruz no sólo tiene la función de indicar un lugar sagrado, sino de protegerlo contra cualquier fuerza que lo pueda perturbar, pues de no hacerlo se corre el riesgo de que se pierda el agua en dicho lugar. ${ }^{7}$

La asociación con el agua y sus beneficios posiblemente sea la razón por la cual uno de los significados atribuidos a este día sea el de tewichib'al, "bendición"; ${ }^{8}$ ya sea cuando aparece como resultado de una pregunta durante la consulta de las semillas $t z$ 'ite', cuando se sueña con situaciones agradables en este día, o cuando en las ceremonias donde se quema copal al momento que se invoca este nawal aparece un remolino levógiro dentro del fuego ceremonial; en todos estos casos, Imox indica la llegada de una gracia divina. Este día se considera adecuado para realizar ceremonias y rezos para arreglar situaciones que implican descontentos, pleitos o incertidumbre; así también para pedir por la tranquilidad de las personas, las ideas o diversas situaciones de vida cotidiana. Uno de los informantes

${ }^{4}$ Los 20 días de este sistema son concebidos como entidades sagradas y animadas, por ello reciben entre los mayas de los Altos de Guatemala la denominación de nawal (Saler, 1969: 17-19; Estrada, 2013: 218).

${ }^{5}$ Plural de ajq'ij, literalmente, "el que trabaja con los días", son aquellos especialistas en el manejo de la cuenta de 260 días, sus pronósticos y sus ceremonias.

${ }^{6}$ Este difrasismo guarda bastante parecido con otro mencionado en el Popol Wuj (2008: 22): "Corazón de la laguna, Corazón del mar”.

${ }^{7}$ Uno de estos peligros es, por ejemplo, el uso de pirotecnia. Un ajq’ij de Totonicapán me comentó que el usar cohetes en las ceremonias es una mala costumbre, ya que su ruidosa explosión "asusta" al nawal que cuida los ojos de agua, y hace que se meta bajo tierra, lo que puede provocar que el agua que mana busque otra salida más alejada, o que definitivamente se seque.

${ }^{8}$ No puedo descartar la posibilidad de que la asociación entre el agua y el concepto de tewichib'al pueda ser tomada de la religión cristiana, en donde se usa dicho líquido para dar la bendición a seres vivos, objetos y lugares, pero lo creo improbable en tanto que en las ceremonias mayas no he observado que se esparza agua con el fin de obtener una purificación, ni para sacralizar nada, lo que sí se hace en la iglesia; en este caso, estas acciones se realizan con el fuego. 
asegura que todas las mañanas cuando lava su cara, da gracias al nawal Imox por la dicha de poder sentir el agua en su cara, y le pide que limpie y aclare su pensamiento por el resto del día, lo que implica cierta relación entre el agua y la idea de "aclarar algo".

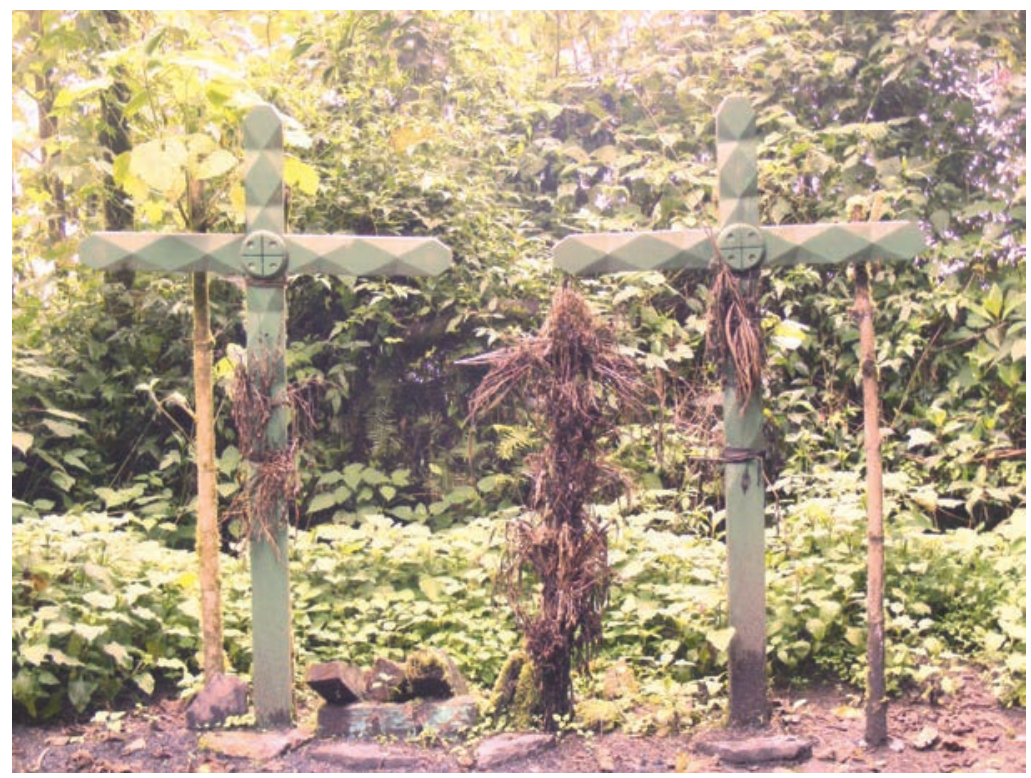

Figura 1. Cruces adornadas que señalan un altar a la orilla de la laguna de Chicabal. Julio de 2010. Fotografía de Canek Estrada

Para hablar en k'iche' de algo que es claro, limpio o diáfano, se utiliza el término saq, que literalmente significa "blanco"; este color está íntimamente relacionado con los significados que se le atribuyen a Imox. Por ello, también es el nawal dueño de los cristales de roca (choq') que poseen los ajq'ijab' en sus altares, los cuales pueden servir como una especie de "contenedores" o receptáculos de ciertas fuerzas de orden sagrado. Para que dichos cristales adquieran más vida, se colocan dentro de grandes vasos o copas llenos de agua (figura 2). Cristales más pequeños se guardan en el envoltorio que contienen las semillas de tz'ite' que sirven para practicar el ch'obonik ${ }^{9}$ — conocido como vara-; en este caso, los cuarzos son llamados u k'ux tz'ite', "el corazón de las semillas de palo de pito" (figura 3) y por lo regular se encuentran en número de 20 dentro de cada envoltorio, que representan a los 20 días-nawales del Cholq'ij. Algunos ajq'ijab' muy hábiles pueden complemen-

${ }^{9}$ Ch'obonik significa "comprensión", y es el término con el que se conoce la técnica con la cual se infiere sobre ciertas situaciones de la vida cotidiana recurriendo a este oráculo de 260 semillas de Erythrina atitlanensis, por medio de las cuales se cree obtener respuestas de los nawales de los días. 
tar el resultado de la consulta de la vara viendo también a través de un cristal de roca con ciertas nubosidades en su interior, asegurando que en las formas que ven en su interior se hallan respuestas a las preguntas de sus pacientes.

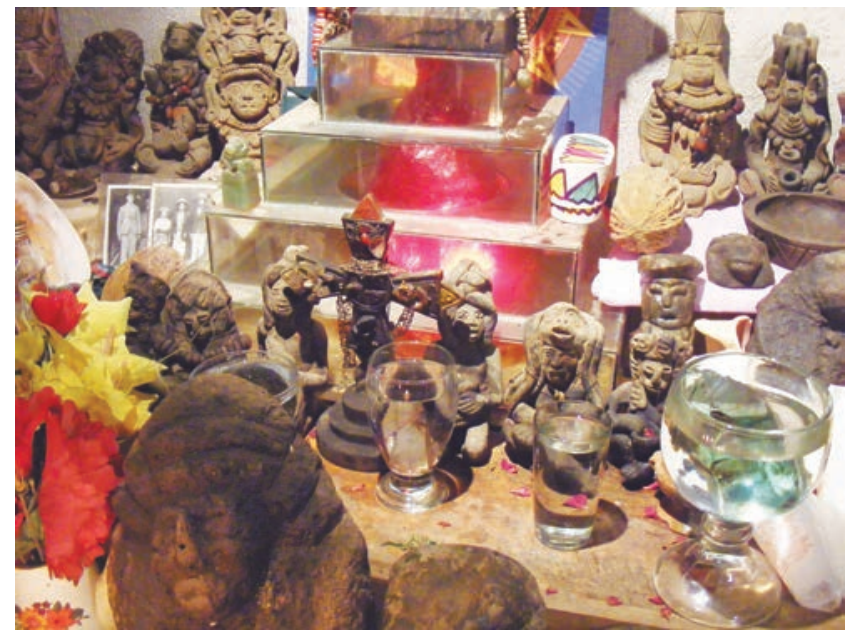

Figura 2. Altar doméstico en Momostenango,

en el que se ponen cristales de roca en copas de agua. Julio de 2009. Fotografía de Canek Estrada

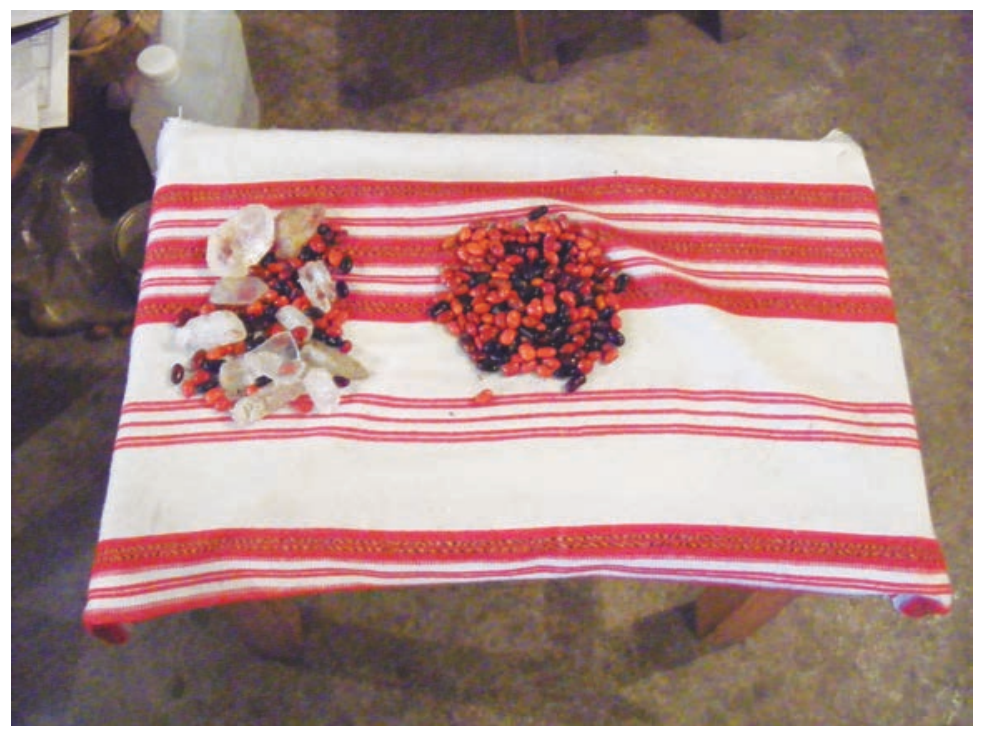

Figura 3. Vara de un ajq'ij tendida sobre una mesa. Del lado izquierdo están los cristales de roca que fungen como "corazón del tz'ite'”. Febrero de 2010.

Fotografía de Canek Estrada 
Algunos ajq'ijab' asocian a Imox con ciertos animales de naturaleza acuática como el delfín y los peces a los que se consideran como una especie de anunciadores del nawal de este día. Aunque al parecer estas relaciones zoológicas con los 20 días-nawales son relativamente recientes y obtenidas de diversas fuentes ajenas a la tradición oral, es interesante mencionar que funcionan como elementos significantes que amplían el sentido de estos días. ${ }^{10}$ Así por ejemplo, uno de los informantes de San Andrés Xecul me comentó que suelen quemar pequeñas cantidades de charales $\operatorname{secos}^{11}$ junto con el copal cuando se invoca a este nawal en las ofrendas, como si con ello se quisiera alimentar a los animales que se relacionan con este día.

Los lugares que se buscan para hacen las ceremonias para este día son preferentemente aquellos donde hay presencia de agua: cataratas, manantiales, lagunas, etc., y destacan por su importancia los altares de Chui Q'apoj', en San Cristóbal Totonicapán, Chui K’axtun y el Cantón Chiyax en San Miguel Totonicapán, la laguna de Lemoa, en el Departamento de El Quiché, y la laguna de Chicabal (figura 4). Esta última —asentada en el cráter del volcán que lleva este mismo nombre y en las cercanías de San Martín Sacatepéquez (Departamento de Quetzaltenango) - es uno de los centros ceremoniales más importantes ligados al ciclo agrícola. Está dentro del territorio de los hablantes de mam, pero la laguna es frecuentada por ajq'ijab' de varios grupos linguísticos (entre ellos los k'iche'), sobre todo alrededor de los días que marcan el inicio de la temporada de lluvias, para pedir el beneficio del agua sobre las cosechas.

\section{El rumbo del norte}

Imox está también relacionado con el rumbo del norte, y esto se debe a que esta dirección se halla del lado izquierdo del mundo, ya que desde la perspectiva cosmogónica k'iche' los rumbos son nombrados a partir de una orientación antropocéntrica, donde el cuerpo humano funciona como un epítome (Tedlock, 2002: 123). De este modo, al situarse una persona con la mirada de frente a la salida del sol, el norte queda hacia el lado izquierdo; por ello a esta dirección se le nombra umoxq'ab' ri kaj, "su mano izquierda del cielo". Curiosamente el color asociado a esta dirección es el blanco, que, como ya mencioné líneas arriba, está relacionado con algunas de las cualidades de este nawal por su carga simbólica. En las ceremonias, se colocan velas blancas sobre el copal que se quemará, cuidando que queden en el sector de la ofrenda que corresponde al norte, contrastando con velas amarillas puestas hacia el lado sur. Como por lo regular los ajq'ijab' se sitúan

${ }^{10}$ Así, por ejemplo, una informante de Santa Cruz del Quiché me relató que en los días Kawuq ella sentía que hacía las cosas muy lentamente, y lo atribuía a que el animal que correspondía a dicho día era la tortuga. Por el contrario, los días Kiej sentía mucha fortaleza y agilidad porque el animal correspondiente era el venado.

${ }^{11}$ Peces de la especie Chirostoma jordani. 
de frente al oriente para rezar, las velas blancas quedan a su izquierda y las amarillas a la derecha. Ambos colores, además de representar a los rumbos norte y sur, son también expresión de la división dual de todas las cosas existentes en el mundo. El significado del color blanco se relaciona con la Luna y con lo femenino, mientras que el amarillo lo hace con el Sol y lo masculino (Estrada, 2010: 42-43).

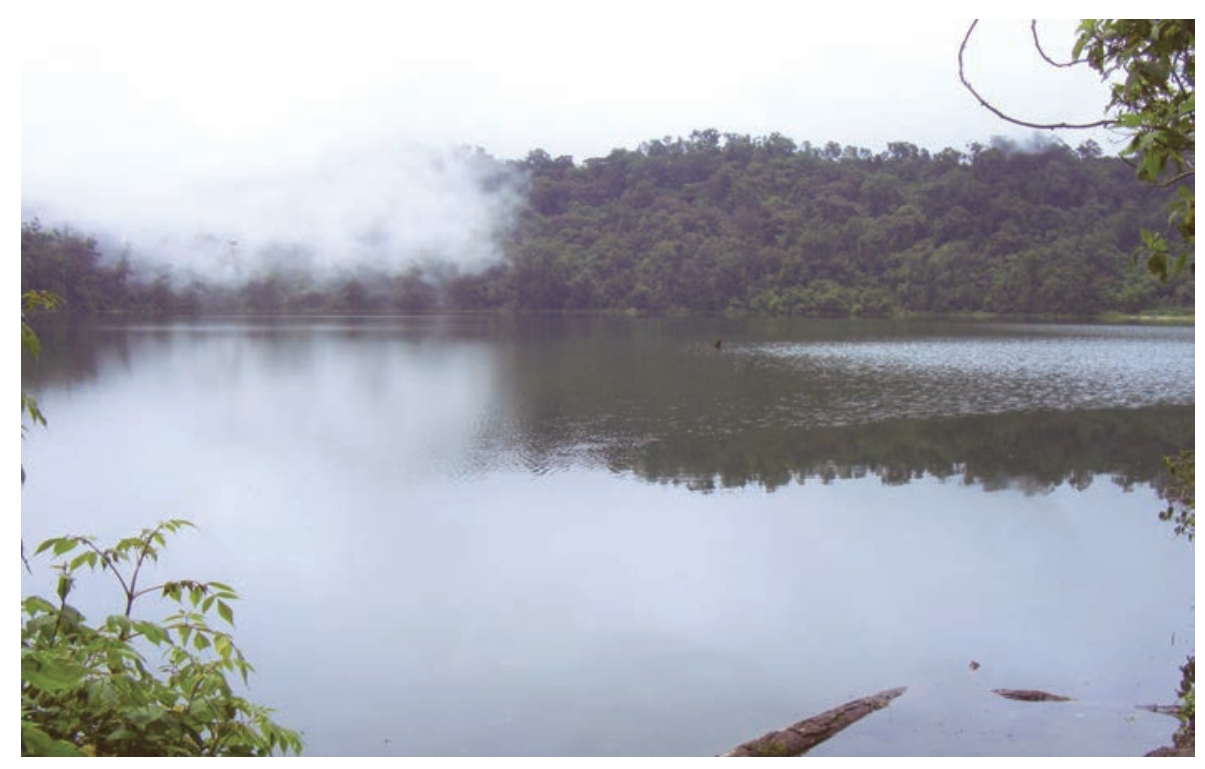

Figura 4. Laguna de Chicabal, uno de los cuerpos de agua más visitados para realizar ceremonias mayas. Julio de 2010.

Fotografía de Canek Estrada

Frente a las objeciones que a primera vista pueden saltar respecto a la asignación de este día a un rumbo cardinal que, efectivamente, no es correspondiente con el orden asignado a los días durante la época prehispánica en los sistemas mesoamericanos (López Austin, 1996: 489, 493), mencionaré que los criterios que siguen los k'iche' hoy día para asignar ciertos días-nawales a las cuatro direcciones que dividen el cuadrante de su cosmograma son diferentes. Contrariamente a los sistemas prehispánicos, en donde hay un orden consecutivo de días orientados hacia el este, norte, oeste y sur respectivamente, entre los k'iche' son los atributos de cada rumbo lo que da razón de ser al día-nawal que corresponde a cada uno de ellos. De este modo, el nawal del oriente es el Aq'ab'al, ya que en k'iche' el nombre de este día significa "aurora"; el día asignado al poniente es el Kame, ya que es la región por la que el sol "muere" y desciende al inframundo; el sur tiene por nawal al Q'anil, que tiene asignado el color amarillo, el cual en k'iche' se dice q'an. El norte pertenece al nawal Imox, por las razones antes descritas. 
Si se conservara el orden que tenían estos días en la época prehispánica, tendríamos que ubicar a Imox en el oriente, a Kame en el norte, a Aq'ab'al en el poniente y a Q'anil en el sur, de todos ellos sólo uno está en este sitio, pero, como ha quedado descrito, este orden carece de relevancia en la actualidad.

\section{El nawal de la locura}

Al interrogar a un ajq'ij acerca de lo que significaba la palabra Imox, la respuesta que obtuve fue que "es el nawal del agua, pero casi como que quisiera decir loco". En ésta y otras entrevistas comprobé el hecho registrado por Schultze Jena (1946: 36) acerca de que, efectivamente, los k'iche' no conocen una etimología exacta para este nombre, por lo que resulta difícil para ellos traducirlo al español, atinando en el mejor de los casos a sugerir una interpretación con base en la similitud fonológica que tiene con otras palabras de la lengua. Todos los informantes con los que pude hablar al respecto logran contestar únicamente por medio de los atributos que se le asignan al día dentro del contexto ritual y calendárico, en vista de que dicho vocablo no existe en el habla cotidiana para nombrar a otra cosa; de igual manera, en diferentes diccionarios (Christenson, 2003: 38; Ajpacajá et al., 2005: 81) no pude sino hallar el mismo resultado. Juan Zapil (2007: 70) menciona al respecto que el término Imox es un nombre que no permite flexión ni derivación.

Hay que mencionar que el referente más parecido en pronunciación dentro de la lengua k'iche', y con el que a menudo relacionan el significado del día, es la raíz mox, que significa literalmente "izquierdo". El parecido entre ambos actúa sobre el espectro de significados que tiene este día dentro de la oralidad, volcándose sobre él aquellos sentidos culturales que engloba el concepto de lo izquierdo para los k'iche'.

El lado izquierdo es entendido como de naturaleza femenina dentro de la taxonomía espacial de esta cultura; sin embargo, el concepto de lo izquierdo también remite a la idea de algo que no está bien hecho, pues la mano zurda es considerada como la mano inhábil, equivocada o débil. En este sentido, las señales que aparecen en forma de "vibraciones" 12 en el cuerpo de un ajq'ij - concretamente en alguna parte de su izquierda - pueden indicar, por un lado, alguna situación relacionada directamente con una mujer, pero, por otro, la negación, la infructuosidad, o el desarrollo de una situación con un resultado negativo para alguna persona.

Mox puede entenderse como lo "siniestro" en el sentido amplio de la palabra, opuesto a lo que se concibe como lo derecho, que es igual a decir lo "bien hecho", lo afirmativo o lo ordenado. ${ }^{13}$ Por eso quizá lo izquierdo represente

12 Estas vibraciones son pequeñas contracciones nerviosas a las que se les asigna un sentido augural, y que se atribuyen a un poder que otorga el relámpago a ciertas personas.

13 Esta concepción la encontramos también en otros grupos mayas, quienes consideran que la mano derecha es la mano verdadera (Sotelo, 1988: 67); de esta manera, la mano izquierda representa lo contrario a lo que es cabal. 
también lo oculto, lo peligroso, lo inestable, lo voluble, lo desequilibrado y la brujería, todo ello característico de la naturaleza de este nawal.

Lo izquierdo también se considera como lo "enredado". Un ejemplo de ello lo podemos encontrar en una práctica ritual llamada saturación, que consiste en inpregnar ciertos objetos con humo de copal a fin de que sean purificados o de que adquieran una "fuerza vital" que los active anímicamente. La saturación que usan varios ajq'ijab' se hace por medio de movimientos circulares, ya sea usando un incensario (de cerámica o de lata), o pasando los objetos sobre el humo de una pira donde se queme copal; para ello se realizan siete movimientos circulares hacia la izquierda, y a partir de este punto se realizan otros seis movimientos hechos en sentido levógiro, ${ }^{14}$ a fin de que se completen 13 vueltas en total, aludiendo a los numerales con que se combina cada día-nawal. Este procedimiento tiene movimientos en ambas direcciones, pues se basa en la complementariedad de opuestos, pero se dejan al final los movimientos hacia la derecha para que los objetos saturados queden "desenredados", es decir, libres de cualquier energía que les impida actuar de manera eficaz, tal y como espera la persona que ha realizado la saturación. De acuerdo a este saber tradicional, los movimientos levógiros serán los que "enrollen" de manera benéfica la fuerza que se pretende impregnar en estos objetos; hacerlo al revés —es decir, hacia la derecha primero y después hacia la izquierda—, sólo "enredaría" esta misma fuerza, dejando al objeto incapaz de trabajar de manera eficiente.

Esta práctica también la podemos encontrar cuando se trata de encender varias candelas frente a un altar para realizar una oración: se piensa que si éstas se colocan alineadas en una hilera y se prenden de izquierda a derecha, la oración podría llegar a tener efecto, pero si esta operación se realiza al revés, es decir, si se colocan y encienden con dirección hacia la izquierda, la petición quedará anulada. También se da el caso en que esta misma forma de encender velas hacia la izquierda se usa para pedir que disminuya la energía vital de una persona a la cual se quiere afectar, causándole una enfermedad o un infortunio. En el mismo orden de ideas, se cree que el rezar contando al revés los 13 numerales con los que se puede combinar el día-nawal de nacimiento de una persona tendrá efectos similares. En dichos casos, ejecutar los procedimientos rituales a la inversa siempre traerá como consecuencia una situación nefasta, indeseable para uno mismo, pero que puede ser usada como arma contra un oponente al que se desea un mal.

Por su relación con el lado izquierdo, Imox se considera el nawal de la locura, lo que no sólo se entiende como trastornos mentales patológicos: el término abarca otras conductas humanas que incluyen la incertidumbre, la inseguridad emocional, las malas decisiones (o la falta de capacidad para decidir), los pleitos, la desesperación, la angustia, el sentimiento de opresión, la propensión a caer en excesos nocivos, entre otras cosas. De este modo, lo izquierdo es también lo "loco"; en otras palabras, es tener la mente alrevesada. Los estados mentales asociados a este

${ }^{14}$ Es decir, en contra de las manecillas del reloj. 
estado son nombrados dentro de la lengua k'iche' como kamoxirik, "se posesiona" o "se vuelve loco"; moxireem, "enojo que causa inestabilidad en el pensar"; moxikiril, "dificultad en tomar decisión”; moxirik, "pérdida del pensamiento"; moxil, "estado en el que la persona no se acuerda de lo que dice y hace" (Tedlock, 2002: 109; Zapil, 2007: 70). Es de destacar que todos estos términos contienen la raíz mox.

Así, Imox es un nawal poderoso, pero su fuerza se desenvuelve en la tensión que se genera entre el orden y el caos. Por dichas concepciones, se considera que los días Imox se caracterizan porque impera una propensión general a confundirse, enojarse o reaccionar de manera arrebatada y poco razonable. Por otro lado, se cree que si el nawal Imox es quien puede causar la locura en la gente, es también quien puede retirarla; por ello las ceremonias que se dirigen a ayudar a alguien que sufre de los males arriba mencionados se hacen también ante este día. También es un día en el que se puede pedir que regrese el ser amado que se ha alejado, o para conseguir casarse con alguien ya separado de un matrimonio anterior.

Concluiré este apartado mencionando que, por todo lo descrito líneas arriba, es inverosímil para los mayas que usan este sistema en la actualidad que Imox pueda ser el primer día con que comienza la cuenta de 260 días, pues este sistema cronológico representa un orden de la acción creadora de la divinidad suprema (Ajaw), y, de acuerdo a las concepciones contemporáneas, es contradictorio que dicho orden comenzara en un día que marca el aspecto caótico del mundo. Por ello, el lugar del primer día de dicha cuenta ha sido dejado —en la gran mayoría de casos reportados - al día B’atz' (Schultze-Jena, 1946: 36; Bunzel, 1981: 334; Goubaud, 1965: 13-14; Rupflin, 1999: 71; Estrada, 2013: 231-232).

\section{El día Imox en otras fuentes documentales}

Este día recibe prácticamente el mismo nombre en todos los grupos mayences de los que se tiene registro de sus calendarios: los chuj, tzotzil, popti', ixil, kaqchikel y tz'utujil lo nombraron Imox o Imux; en lengua pocomchi' fue Mox, y en maya yucateco, mam y aguacateco, Imix o Imx (Thompson, 1960: 68; Ayala, 1978: 388390). Sin embargo, no se conoce un significado etimológico preciso sobre estas denominaciones: en k'iche' no hay etimología cierta de la palabra (como mencioné líneas arriba); entre los chuj y los pokomchi’ es la palabra para decir "escarabajo" (ALMG, 2003a: 65), y en mam con ella se nombra a las glándulas mamarias. ${ }^{15}$ (ALMG, 2003b: 47). En maya yucateco, el Diccionario maya nos dice que "[...] es igualmente el nombre esotérico de la ceiba, el árbol madre de los mayas y simboliza la dualidad tierra-agua, origen de la vida” (Barrera et al., 1980: 268).

\footnotetext{
15 En la mayor parte de las lenguas mayas, la raíz im hace alusión a los senos femeninos, pero sólo en el caso del mam hay una equivalencia homófona entre ambos conceptos; aun así, esto llevó a algunos investigadores a pensar que la representación gráfica del día hace referencia a dichos órganos (Brito, 1981: 37).
} 
En vista de la falta de una traducción etimológica precisa, creo pertinente remitir a los diferentes elementos sígnicos que rodean a dicho concepto.

En las inscripciones mayas, el glifo de este día corresponde a la figura que también se encuentra en el botón del lirio acuático; cuando está fuera de contexto calendárico este logograma se lee como $\mathrm{Ha}^{\prime}$, "agua" (Thompson, [1950] 1960: 72; Calvin, 2004: 34). Es importante remarcar el hecho de que también una variante del glifo de este día hallado en Piedras Negras corresponde a la cabeza de un saurio u ofidio que carece de la mandíbula inferior, la cual podríamos decir que es equivalente o cercana a la caracterización de este día en los calendarios del centro de México, en donde se le llamó Cipactli en náhuatl, y que representa a un lagarto con espinas en el cuerpo y sin la mandíbula inferior (figura 5).
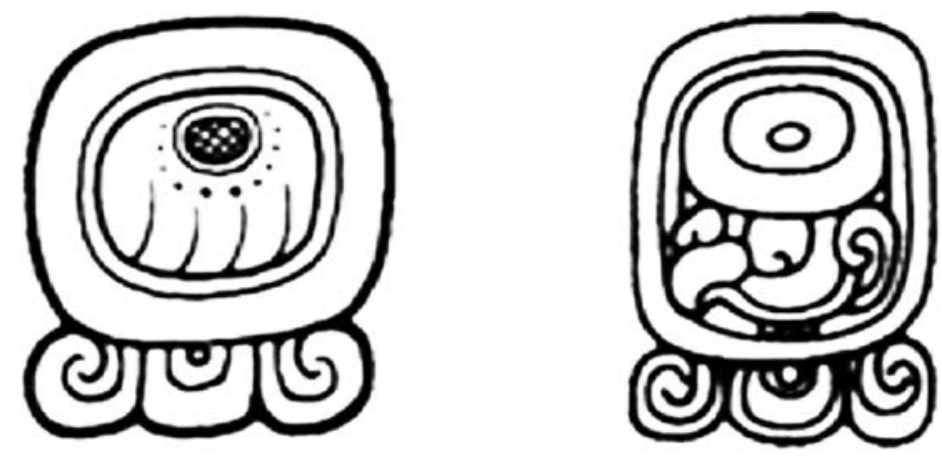

Figura 5. Glifos para el día Imix en el periodo Clásico Tomado de Calvin (2004: 8)

William Gates ([1931] 1978: 19-20) notó que este glifo se encuentra repetidamente en los códices mayas asociado al glifo de KAN, "maíz", en varias ocasiones en contextos referentes a ofrendas, y que juntos forman un difrasismo que significaría "comida y bebida". Para Thompson, este glifo y el significado del día en general tenían que ver con la tierra y la abundancia por extensión, pues retoma las informaciones etnográficas sobre todo de los ixil, popti' y mam, en donde el sentido del día tiene que ver con la santa tierra y la siembra del maíz: "it is quite clear that this day symbolizes the earth and, by extension, abundance... Imix, therefore, was the eart moster, the cocodrile, whose back formed the surface on the earth; the wather lily was probably his symbolic form; abundance was his aspect, and the earth his domain" (Thompson, 1960: 70-73). El trabajo etnográfico realizado por Steward Lincon (1942) entre los ixil parece corroborar el carácter ctónico que le atribuyó Thompson, ya que encontró que, para ellos, el día Imush significa la tierra, y que "era favorable para orar por la casa y la familia a fin de que el mundo o la tierra no los castigue" (Villa Rojas, [1968] 2003: 160).

Referente al augurio que se daba a Imix, en el Chilam Balam de Kaua (Barrera y Rendón, 2005: 136) está documentado lo que se decía en la época colonial sobre 
la persona que nacía en este día: "Imix: El pan de maíz. Nicté, La-flor-de-mayo es su anuncio. Nicté, La-flor-de-mayo, es su árbol. El cometa es su anuncio. Pecador libidinoso. Deshonesto. El más bellaco hombre. Indeciso, dudoso".

\section{Nawal Imox y la ceiba}

Una de las referencias más tempranas que tenemos respecto al nawal Imox está en la obra de Núñez de la Vega (1702), quien relata que en Chiapas (posiblemente entre tzeltales o tzotziles) está vinculado con los árboles de ceiba:

[...] hoy en día en los calendarios más modernos está corrupto el nombre latino de Nino en Imos, pero colocado siempre en primer lugar, y su adoración corresponde a la ceiba, que es un árbol, que tienen en todas sus plazas de sus pueblos a vista de la casa del cabildo, y debajo de ella hacen sus elecciones de alcaldes, y la sahuman con braseros, $\mathrm{y}$ tienen por muy asentado que en las raíces de aquella ceiba es por donde viene su linaje. $Y$ en una manta muy antigua la tienen pintada, y algunos maestros nagualistas grandes que se han convertido han explicado lo referido y otras muchas cosas (Núñez de la Vega, 1988: 275).

Este texto colonial hace referencia explícita a que el nombre del día se refiere al mencionado árbol de la familia de las Bombacaceae, ampliamente distribuido por el sureste mexicano y Centroamérica. Los mayas atribuían varios aspectos cosmogónicos a este árbol: era llamado yaxche' en las Tierras Bajas, término que puede significar tanto "árbol verde" como "primer árbol”, o "árbol primigenio", ya que yaax puede entenderse como "verde-azul" o como "primero" (Freidel et al., 1999: 51). Era considerado el eje que sostenía en su sitio los tres niveles de cielo, tierra e inframundo, pero también lugar de tránsito que permitía el intercambio de las diferentes fuerzas sagradas que radicaban en dichos niveles.

De propia mano de los depositarios de las tradiciones orales de la Península de Yucatán tenemos testimonios escritos acerca del importante papel que desempeñaba la ceiba en los mitos de creación. El Chilam Balam de Chumayel narra uno de ellos, en el que se desata la destrucción del mundo que sobrevino de una confrontación en la que las deidades del inframundo - Bolon ti K'u- agredieron y robaron sus insignias a los dioses celestes —Oxlajun ti K'u—; de todo ello sucedió una inundación que cubrió la tierra:

Y fueron enterrados por la orilla de la arena en las olas del mar. Y entonces, en un solo golpe de agua, llegaron las aguas. Y cuando fue robada la Gran Serpiente, se desplomó el firmamento y hundió la tierra. Entonces los Cuatro dioses, los Cuatro Bacab, lo nivelaron todo. En el momento en que acabó la nivelación, se afirmaron en sus lugares para ordenar a los hombres amarillos.

Y se levantó el Primer Árbol Blanco [Sac Imix Che, "Ceiba blanca”], en el Norte. Y se levantó el arco del cielo, señal de la destrucción de abajo. Cuando estuvo alzado el Primer Árbol Blanco, se levantó el Primer Árbol Negro [Ek Imix Che, "Ceiba 
Negra”], y en él se posó el pájaro de pecho negro. Y se levantó el Primer Árbol Amarillo [Kan Imix Che, "Ceiba Amarilla”], y en señal de la destrucción de abajo, se posó el pájaro de pecho amarillo. Y se oyeron los pasos de los hombres amarillos, los de semblante amarillo.

Y se levantó la Gran Madre Ceiba [Yaax Imix Che, Ceiba Verde"], en medio del mundo, como recuerdo de la destrucción de la tierra. Se asentó derecha y alzó su copa, pidiendo hojas eternas. Y con sus ramas y sus raíces llamaba a su Señor (Chilam Balam de Chumayel, 2001: 88-89). ${ }^{16}$

Estos árboles se revelan aquí como un elemento ordenador del cosmos al ocurrir y terminar un cataclismo de origen divino, que tuvo como consecuencia la destrucción de un mundo anterior. En este texto se les nombra Imix Che, es decir, que el nombre del día que nos aborda es parte de su denominación; de la misma manera, se les asigna un color distinto a cada uno, concordante con la región en donde se colocaron: roja al oriente, blanca al norte, negra al poniente, amarilla al sur, y, la principal, verde-azul ${ }^{17}$ en el centro del mundo. En este orden de ideas creo que corresponde a lo mencionado en otra parte del mismo Chilam Balam de Chumayel (2001: 118), cuando se describe cómo fue creado el mundo en relación con los días de Uinal: "En el Once Ix (Imix) sucedió que hizo las piedras y los árboles". También llama la atención que en el periodo Clásico el dios patrono (o mejor dicho los dioses patronos) de este día sean los Pawahtuno'ob, deidades que sostenían el cielo en las cuatro direcciones del mundo, distribuidos de manera similar a las ceibas mencionadas. La imagen de Pawahtun es también la variante de cabeza y de cuerpo completo del número cinco en las series iniciales de monumentos de diversos sitios.

\section{Relaciones sígnicas con el cocodrilo}

Otro de los aspectos simbólicos que frecuentemente podemos encontrar asociado a este día es el de un animal al que comúnmente se le ha llamado en la literatura mesoamericanista como "monstruo" — a fin de no atribuirle una identificación biológica exacta-, pues en varios casos se trata de animales con aspecto fantástico; pero, salvo excepciones, es claro que están inspirados en los saurios del orden de los Crocodylia.

La asociación entre nuestro día y este ser se hace visible en primer lugar porque el nombre equivalente de este día durante la época prehispánica en el centro de México era Cipactli (figura 6), que significa "cocodrilo", o en algunos casos

\footnotetext{
${ }^{16}$ Como se asienta en el pie de página de esta edición, en el texto falta mencionar la erección de la Ceiba del rumbo del oriente, de color rojo, Chak Imix Che, que, sin embargo, viene mencionada en otra parte de esta misma obra llamada "Libro de los linajes" (Chilam Balam de Chumayel, 2001: 41).Otra traducción de este pasaje se puede confrontar en Barrera y Rendón (2005: 100-101).

${ }^{17}$ En las lenguas mayas se usa la misma categoría linguiística para los colores verdes y azules.
} 
"tiburón”, "pejelagarto" o "espadarte" (Caso, 1967: 8-9). En segundo lugar, una de las variantes glíficas con que es representado este día en las inscripciones es con la cabeza de un reptil desprovisto de la mandíbula inferior, a semejanza de la forma en que se representaba al cocodrilo en otros estilos artísticos mesoamericanos, como ocurre, por ejemplo, en el conocido como Mixteca-Puebla.

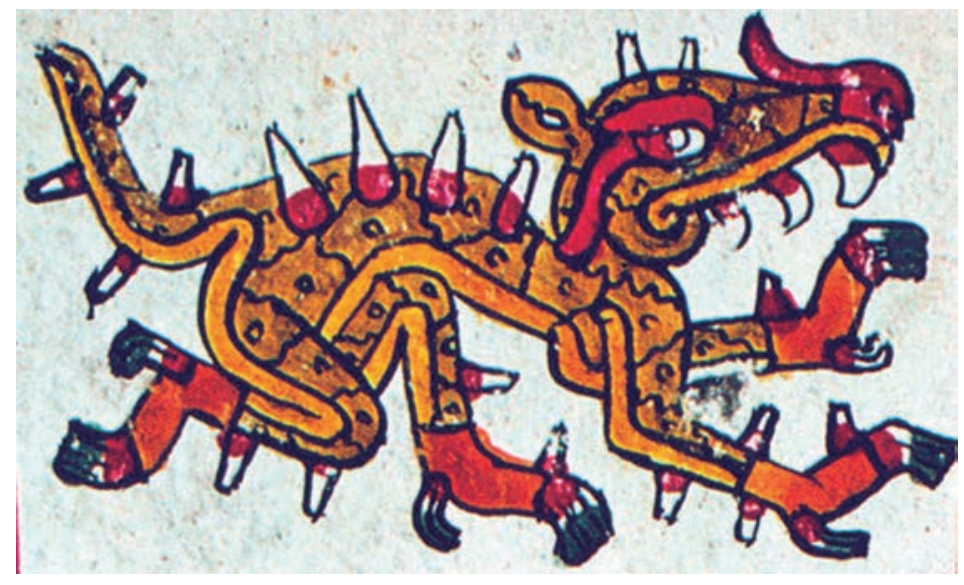

Figura 6. Día Cipactli. Códice Borgia, lámina 21 (detalle)

En el área maya este ser recibió varios nombres —atestiguados en los documentos coloniales de Tierras Bajas-, como Itzam Cab, Itzam Cab Ain y Chac Mumul Ain, que se pueden traducir como "Itzam Tierra", "Itzam Tierra Cocodrilo" y "Gran Cocodrilo Lodoso" respectivamente (Garza, 1988: 203).

Thompson (1960: 72) señala que este ser se puede distinguir por los apéndices de lirio acuático que porta: "The flower of the water lily presumably was chosen as the symbolic form of Imix, partly to avoid confusion with other reptilian monster [...]". El distinguido mayista concluye que el día Imix remite al dragón terrestre que flota sobre las aguas, y que significa tierra y abundancia por extensión; afirma además que los mayas creían que el mundo descansaba sobre el tórax de un enorme caimán o lagarto, y que éste, a su vez, flotaba sobre una vasta laguna. Tal vez como menciona Arias (2004: 62), estamos ante un ser que encarna muy puntualmente este binomio simbólico: "Aquí se encuentran dos elementos importantes, la tierra y el agua. Así tenemos que el cocodrilo es indudablemente un personaje de fertilidad. Es un animal que vive en el agua y en la tierra, que con una fecunda a la otra y crea vida".

Las flores de lirio acuático o nenúfar que lleva este ser son también un atributo iconográfico de todas las deidades terrestres y subterráneas en general, por ello es posible encontrarlas en algunas representaciones de jaguares y del dios de la muerte. El nenúfar aparece mencionado como naahb en las inscripciones, palabra que también designa cuerpos de agua como lagos, charcas o el mar (Kettunen y 
Helmeke, 2005: 78). Por su parte, Ayala (1978: 394) opina que "tanto los ejemplos procedentes de Izapa, como los de Yaxchilán y Palenque, en donde el mismo animal está asociado con lirios acuáticos, nos lleva a pensar que el dios estuvo en un principio asociado en forma más directa con el agua que con la tierra”. Según Vargas y Arias (2005: 5), estas asociaciones son resultado de la observación de los hábitos de comportamiento de estos animales: los cocodrilos se especializan en buscar agua fresca, pues su cuerpo lo requiere; de este modo, ayudan al abastecimiento de este líquido en los estanques donde viven.

El vínculo mítico entre el cocodrilo y la lluvia está referido en una serie de corpus textuales procedentes de diversas regiones de las Tierras Bajas mayas, que van desde el periodo Clásico hasta la época colonial. Se refieren específicamente con una especie de "diluvio" ocurrido en los tiempos de la creación.

La plataforma jeroglífica del templo XIX de Palenque es uno de los mejores ejemplos de un texto del Clásico en donde aparece dicho mito; ${ }^{18}$ su inscripción jeroglífica menciona acontecimientos que realizaría el dios GI durante el pasado mítico, destacando un evento en el cual decapita a un cocodrilo durante un día 1 Eznab, y con ello ocasiona un diluvio o una inundación a causa de la sangre que se derramó (Stuart, 2010: 60, 68; Velásquez, 2006: 1). Los nombres con que la inscripción se refiere a este cocodrilo son Way Paat Ahiin, Tz’ijb’al Paat Ahiin, "Caimán de cavidad [en la] espalda, caimán de espalda pintada"19 (figura 7).

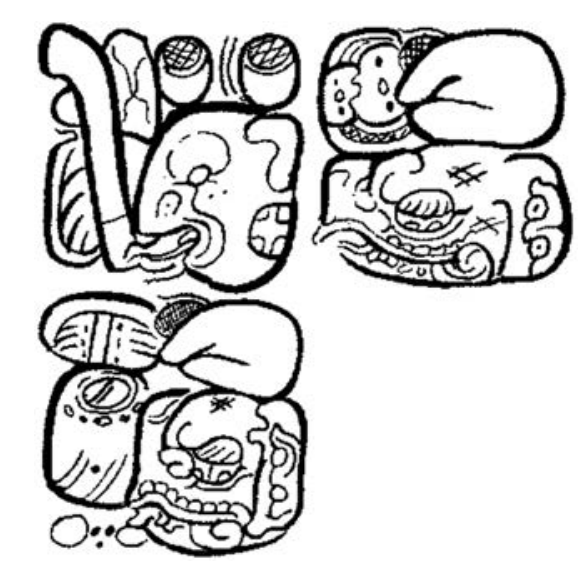

FIGURA 7. Glifos del tablero de la plataforma del templo XIX, lado sur. Esta inscripción alude al nombre del "Caimán de cavidad [en la] espalda, caimán de espalda pintada”. Tomado de Stuart (2010: 70)

\footnotetext{
18 Este monumento fue inaugurado en el año 734 d.C. durante el reinado de K'inich Ahkal Mo' Nahb'.

${ }^{19}$ En opinión de Velásquez (2006: 2), estos nombres son en realidad frases pareadas que hacen alusión al mismo ser, siempre que se ha atestiguado que en las inscripciones mayas se usa el paralelismo como un recurso de equivalencia sintáctica.
} 
Entre los mayas yucatecos se tuvo también la creencia en un lagarto, al cual llamaron Itzam Cab Ain. Al igual que su contraparte palencana, su papel mítico fue el de generar un diluvio, aunque en este caso de agua; testimonio de ello es la lámina 74 del Códice Dresde, así como los pasajes contenidos en los libros del Chilam Balam provenientes de Tizimín y de Maní (Velásquez, 2006: 6).

De la misma manera, se tiene registro que durante los ritos de año nuevo en la Península de Yucatán, la figura del reptil fungía como símbolo de una destrucción anterior:

\begin{abstract}
Tuvieron noticia de la creación del mundo y un creador de cielo y tierra, y decían que éste que los creó, no podía ningún hombre pintarle como era. Tuvieron también noticia de la caída de Lucifer y del Diluvio, y que el mundo se había de acabar por fuego, y en significación de esto hacían una ceremonia y pintaban un lagarto que significaba el Diluvio y la tierra, y sobre este lagarto hacían un gran montón de leña y poníanle fuego y, después de hecho brasas, allanábanlo y pasaba el principal sacerdote descalzo por encima de las brasas sin quemarse, y después iban pasando todos los que querían, entendiendo por esto que el fuego los había de acabar a todos (Relaciones Histórico-Geográficas, 1983, I: 72).
\end{abstract}

Todas estas referencias nos dejan pensar que, en los mitos de creación de diferentes regiones del área maya, el cocodrilo fue entendido como una reminiscencia a una deidad dema, la cual, al ser destruida, causó un cataclismo que acabó con un orden anterior del mundo, y que por medio de la posterior desarticulación de sus partes, así como de la erección de postes en las cuatro esquinas del cosmos, se logra instaurar el equilibrio del espacio habitable en su estado actual. Aquí agua, diluvio, lagarto y ceiba son elementos del mito, y aunque aparentemente sean distintos, son partes de un complejo simbólico que se articula en un texto que nos habla del fin de un estado de caos para dar pie a un orden de las cosas.

Dicho texto es apreciable también en diversas representaciones visuales en las que la figura del cocodrilo se conjuga con otros elementos iconográficos durante la época prehispánica desde tiempos tan tempranos como el periodo Preclásico; ejemplo de ello lo podemos encontrar en la ya conocida estela 25 de Izapa (figura 8), en donde las raíces del árbol representado adquieren la forma de un cocodrilo. Resulta sumamente interesante la comparación de estos mitos con los de los nahuas del centro de México, pues diversas fuentes dan testimonio de relatos con alto grado de paralelismo. Uno de ellos es aquel registrado en la Historia de los mexicanos por sus pinturas, donde se narra que el cuerpo de la diosa Tlaltecuhtli es desmembrado para formar el cielo y la tierra, acto seguido por la necesaria labor de colocar árboles en las cinco regiones del cosmos. La narración relata que los dioses Quetzalcóatl y Tezcatlipoca

[...] luego criaron los cielos, allende del treceno, e hicieron el agua y en ella criaron a un peje grande, que se dice Cipactli, que es como caimán, y de este peje hicieron la tierra, como se dirá [...], Después, estando todos los dioses juntos, hicieron del 
peje Cipactli la tierra, a la cual dijeron Tlaltecutli, y píntalo como dios de la tierra, tendido sobre un pescado, por haberse hecho de él (Historia de los mexicanos por sus pinturas, 1965: 25-26).

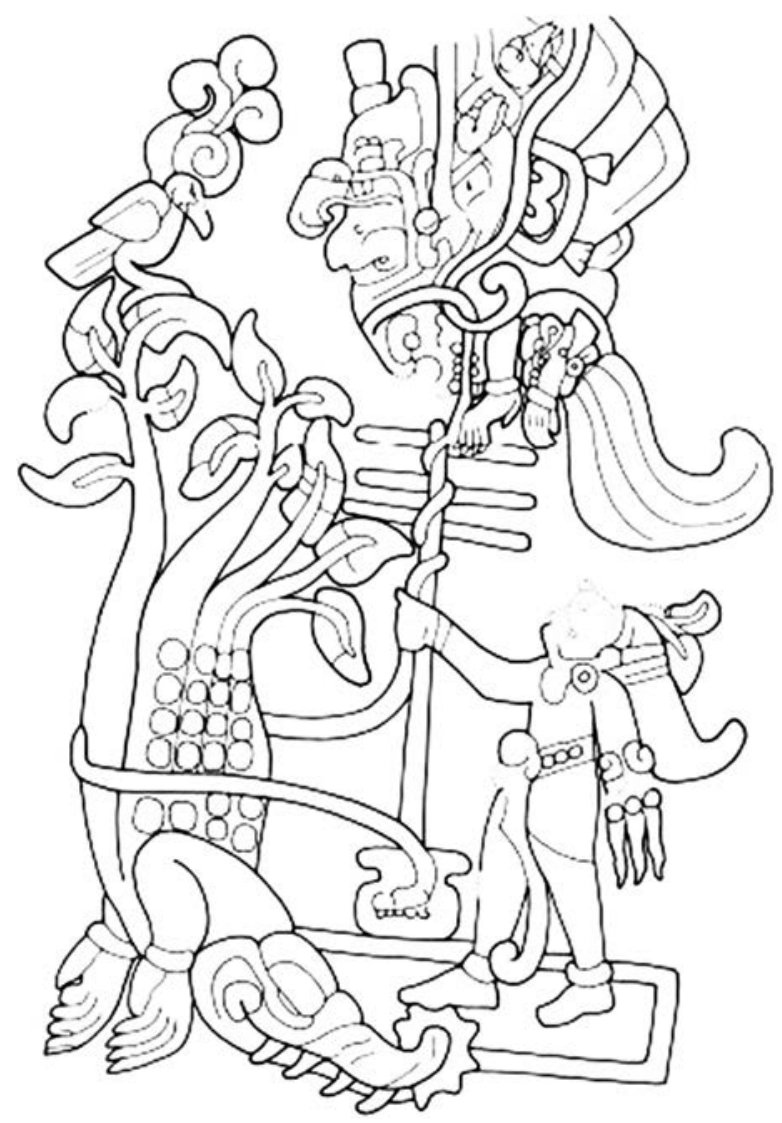

Figura 8. Estela 25 de Izapa, Chiapas. Dibujo de Oswaldo Chinchilla

En la versión nahua de este mito no encontramos referencias acerca de que la mutilación de la diosa Cipactli sea causa de un diluvio o una inundación, pero es claro que ella se encuentra en un medio acuático. La vinculación entre este ser sagrado con la tierra va acompañada al mismo tiempo con el referente al agua, en tanto que es el agente destructor del orden anterior, o el ámbito preterrestre que sirve de escenario para la creación de la tierra.

Si estos mitos tienen una implicación panmesoamericana —más allá de las lenguas, los territorios y las temporalidades-, y nos muestran cierta uniformidad en las concepciones míticas y cosmogónicas de los pueblos que habitaron esta 
área cultural, tenemos una herramienta para intentar comprender el sentido profundo que pudo tener el día Imox-Imix-Cipactli para aquellos pueblos que usaron el calendario de 260 días. Preliminarmente podemos entender que nuestro día tiene que ver con los mitos que nos hablan de una época primordial en la que destaca la prevalencia del agua como estado original anterior a todo lo demás; en este estado del mundo existe un ser precursor de la tierra que debe ser destruido por un dios o dioses, a fin de que del caos originado por dicho cataclismo se pueda reconstruir el medio habitable favorable para la existencia de la vida, es decir, el cielo y la tierra tal cual los conocemos. Se refiere concretamente a este lagarto que se constituye como potencia que anima al nuevo tiempo —el de la trascendencia divina - nacido de un estado anterior negado a la acción creadora de los dioses (López Austin, 2006: 59-65), y en donde la penumbra, el reposo y el desorden imperan.

\section{Discusión}

Es un hecho que en la actualidad gran número de especialistas rituales k'iche' hablan de la naturaleza acuática de este día-nawal, ya que para ellos encarna a la energía sagrada que domina todo lo relacionado con el vital líquido; es —en palabras de un $a j q^{\prime} i j$ - el "santoral del agua". De por qué tal relación no está documentada en los trabajos etnográficos anteriores a la década de los años noventa del siglo xx, es decir, antes de que cobrara fuerza el movimiento de la Espiritualidad Maya, planteo algunos posibles escenarios.

Una es que este concepto, tal y como se entiende en la actualidad entre los ajq'ijab', sea consecuencia de la reapropiación reciente de un texto proveniente del medio académico especializado en la cultura maya. Tendríamos entonces que proponer que trabajos como el de Gates (1978), Schultze-Jena (1946) y Thompson (1960), entre otros, fueron leídos por los propios mayas —en especial por aquellos que contaban con los medios y las oportunidades para realizar una investigación sistemática acerca de temas de epigrafía, iconografía, calendario, etc. - y posteriormente retomaron sus ideas, plasmándolas de manera consciente dentro de su propia tradición oral. Sería necesario aceptar, entonces, que esta gente haya difundido estos "nuevos conocimientos" en sus propias comunidades y en especial entre los guías espirituales. O puede ser el caso de que un antropólogo entablara una relación de confianza con algún o algunos especialistas calendáricos tradicionales, y les enseñara los últimos avances del conocimiento que se estaba produciendo en esa época acerca del calendario, lo cual sería bien recibido por ellos y rápidamente esta información fuera incluida en su campo de significación.

En estos posibles escenarios impera la premisa de la intromisión de un texto ajeno a la tradición oral. No podemos negar que este hecho sea una posibilidad real dado que en Guatemala se vive un momento de reivindicación de la identidad en donde la revaloración del pasado prehispánico es un eje importante para 
definir lo que los mayas entienden como su cultura, y hoy día existe un número importante de mayas de diferentes comunidades linguísticas en Guatemala interesados en el estudio y desciframiento de los textos antiguos provenientes de las llamadas Tierras Bajas. Pero estas explicaciones tienen el detalle de que, quizás en su sencillez, caigan desafortunadamente en una idea ingenua de que los procesos semióticos se dan en forma unidireccional, o de que un texto es tomado tal cual y automáticamente agregado a lo que ya se tenía dentro del bagaje cultural propio.

En primer lugar, y aunque en algunos textos escritos por mayas aquí referidos (Yool y Curruchich, 1999: 13; Guorón et al., 2002: 77) encontramos que se hace referencia al lagarto como uno de los significados de este día, durante mi propio trabajo de campo no encontré quién mencionara siquiera una vez a éste o cualquier otro reptil. Quienes escribieron estos textos muy seguramente conocen estudios acerca del calendario mesoamericano y lo combinan con los saberes tradicionales, pero en el acervo oral de la mayoría de los guías espirituales no hay mención de reptil alguno en las oraciones o augurios asignados a este día-nawal.

Por otra parte, no estoy seguro de que los especialistas rituales conozcan el significado de los glifos de los días que les han asignado los epigrafistas. Si bien es cierto que manejan estos glifos como parte de la iconografía que se puede apreciar dentro de las ceremonias, así como decorando varios objetos rituales hoy día, al parecer, con contadas excepciones, hay un desconocimiento general de las interpretaciones que hacen los mayistas acerca de ellos. Por el contrario, existen varios casos de interpretaciones "alternativas" de dichos glifos elaboradas por los propios mayas, las cuales tienen la particularidad de corresponderse con las concepciones contemporáneas acerca de los atributos dados a los 20 nawales del Cholq'ij. Así, por ejemplo, el glifo del día Imix es para algunos ajq'ijab' la representación de una mano zurda empuñada, ${ }^{20}$ en tanto que el significado que se le da a dicho día tiene que ver con el lado izquierdo; para ellos el glifo no tiene relación con la flor de lirio acuático.

Estos hechos me hacen cuestionar seriamente la supuesta reincorporación de un texto procedente de fuera de la esfera de la oralidad maya y concretamente de las concepciones k'iche', pues, de ser el caso, sería más notoria y palpable la influencia de los símbolos asignados a este día procedentes de la literatura académica mayista, como son el lagarto y la flor de lirio, ambos prácticamente ausentes dentro del bagaje sígnico atribuido al nawal Imox a nivel de la oralidad contemporánea de la región.

Otra posibilidad que queda latente es la de que los etnógrafos que registraron los significados de los días antes de la época mencionada no hubiesen anotado nada respecto a la relación de este día-nawal con el agua por las limitantes pro-

\footnotetext{
${ }^{20} \mathrm{Al}$ parecer, en los años sesenta del siglo xx, un señor de nombre Calixto, del pueblo de Olintepeque, fue el primer ajq'ij que comenzó a interpretar estos glifos a su entender, por medio de un libro de Morley (Fabián Frías, com. pers., 2009).
} 
pias a las que se enfrenta el investigador al tratar con los informantes, como es el que la persona entrevistada decida no revelar todo lo que en realidad sabe sobre tal o cual tema por el que se le pregunta; o quizá que el etnógrafo se limite a registrar la información obtenida de un único informante o de sólo una comunidad. Pero en este caso resulta difícil creer que varios investigadores obtuvieran similares resultados con la misma aparente carencia.

Para intentar acercarme a una respuesta que pueda dejar satisfecha la cuestión, me inclino por proponer que estamos frente a un texto que fue temporalmente olvidado, y que a razón de un estímulo producto de la nueva situación en la que se vio envuelto el uso del Cholq'ij, se reincorporó al campo de significación k'iche', aunque solamente en los aspectos que resultaron significativos para la cosmogonía contemporánea de dicha cultura, quedando en el olvido temporal aquellos que carecen de sentido y que en realidad no les resultan relevantes.

Uno de los conceptos que nos ayudarán a entender esta propuesta es el que acuñara Iuri Lotman en torno a lo que él llamó la semiosfera (1996: 21-42). Explica que todo objeto de la cultura, así como sus sistemas precisos, no tienen capacidad de trabajar por sí mismos si no se encuentran sumergidos dentro de un continuum semiótico con formaciones de diversos tipos y en distintos niveles de organización, siendo la semiosfera quien cumple ese papel, ya que se trata de una esfera abstracta en la que se dan los fenómenos en torno a la comunicación, la circulación de información, su retención, creación y transformación en general; fuera de este campo no es posible que exista la semiosis.

La semiosfera es de un espacio delimitado y hasta cierto punto homogéneo, pero sus límites se cierran frente a textos que no pueden participar dentro de la circulación de información y la creación de sentido. Aunque más allá de estas fronteras no es posible el desarrollo de dichos procesos, no es un espacio hermético: existen elementos que cumplen la función de "filtros-bilinguies", los cuales traducen lenguajes y códigos que se hallan fuera de este campo, motivando una circulación constante de textos desde el interior de la semiosfera hacia afuera, y de manera inversa, de textos alosemióticos provenientes de fuera del campo a su interior. Esta función hace posible que puedan existir para la realidad comprensible de una cultura elementos que vienen de afuera de su campo de significación, $\mathrm{y}$, al contrario, que puedan entrar en contacto los textos propios con otras semiosferas y que éstos se incorporen dentro de ellas.

Durante la traducción de los textos ajenos para su asimilación dentro del campo propio, se tiene que recurrir a los códigos que determina la cultura a la que pertenecen estos filtros, que no siempre serán concordantes con aquellos originales que daban sentido al texto del exterior; ello creará un espacio de flexibilidad y de búsqueda de analogismos a fin de solventar la tensión que existe entre ambos. Determinados niveles de los mismos deben ser comunes y formar conjuntos que se intersecten, pero en otros niveles aumenta la gama de la intraducibilidad, por lo que se anula la posibilidad de obtener el texto inicial, lo cual constituye precisamente el mecanismo de surgimiento de nuevos textos. Es en 
este momento cuando se pone en operación la capacidad creadora, resultando un texto hasta cierto punto impredecible de este proceso.

Bajo estas premisas, propongo que la transformación del significado atribuido al día-nawal Imox pudo haberse dado de la siguiente manera:

En una época remota en la que se consolidó el calendario de 260 días como una manifestación cultural mesoamericana, este día se relacionó con los símbolos propios a los mitos que narraban la instauración de un orden por sobre un estado anterior diferente y percibido como caótico. En este sentido, el agua, el Monstruo-lagarto de la tierra y los árboles jugaban un papel protagónico. En algún momento del devenir histórico de la cultura imperante en los Altos de Guatemala, algunos de estos símbolos cosmogónicos dejaron de responder a la explicación que ellos mismos tenían acerca del origen del mundo, y fueron relegados a un ámbito periférico de su semiosfera.

El proceso de conquista y colonización significó una inclusión violenta y extremadamente drástica de gran cantidad de textos nuevos que se incorporaron a la semiosfera de los pueblos originarios, muchos de los cuales llegaron a ocupar parte de las estructuras nucleares de ella. Dentro de la esfera compartida por los mayas de los Altos de Guatemala, aunque el Cholq'ij se sostuvo dentro de aquellos textos que funcionaban como memoria de la cultura - y por lo tanto una de sus estructuras nucleares-, muchos de los textos integrados a su sistemas pasaron también a un campo periférico dentro de la semiosfera, mientras otros se mantuvieron.

Si bien hubo diferentes niveles de continuidad o de olvido de los textos propios a cada uno de los 20 nombres y significados de los días de este sistema, en los casos en los que hubo mayor grado de "olvido" —léase éste como transición de un texto a la periferia de la semiosfera, por lo tanto un olvido temporal y potencialmente no permanente - se dio un mayor ejercicio de la capacidad creadora, asignándoles nuevos sentidos (o nuevas perspectivas de los anteriores) a fin de que dichos textos fueran funcionales con las nuevas condiciones y paradigmas que imperaban dentro de su campo de significación. Para que este proceso fuera posible, los k'iche' echaron mano de los recursos culturales a su alcance y que provenían de las estructuras nucleares. Hablando en concreto de nuestro díanawal estudiado, es posible que, al perder la noción de lo que etimológicamente significaba el nombre del día Imox, recrearan su sentido por medio de paronomasia con la palabra mox, y le atribuyeran los sentidos que de ella se derivan en el pensamiento k'iche'. A ello correspondería la información que encontraron los etnógrafos referidos durante gran parte del siglo xx. En este tiempo, los sentidos de alrevesado, locura, disgusto, brujería, ocultismo, etc., ocuparían un lugar nuclear dentro de la comprensión de este día y del sistema en general.

En alguna parte del periodo comprendido por las décadas de los años ochenta y noventa del siglo pasado, justo durante el proceso de redefinición de la identidad maya de Guatemala, y en el cual el uso del Cholq'ij jugaba un papel importante, algunos individuos (intelectuales mayas) que pudieron estar en contacto 
con los textos provenientes del medio académico mayista —que jugarían el papel de filtros-traductores a los que se refería Lotman-, podrían haber planteado de nueva cuenta la relación entre este día-nawal y su naturaleza acuática, así como la referencia al Monstruo-lagarto de la tierra. Tales ideas, provenientes en ese momento del exterior de la semiosfera k'iche', interactuaron con aquellos textos relegados a la periferia, los cuales no eran profundamente significativos hasta antes de este momento, pero recordaban la relación de Imox con el agua.

Si bien algunos de estos individuos que funcionaron como traductores de textos alosemióticos hacen mención de la relación entre el día Imox y el lagarto, éste no fue un texto que prosperara en la oralidad de la semiosfera k'iche'ana, en tanto que no representó algo significativo. En cambio, la relación con el agua fue sumamente importante, por lo que, al ser estimulado por un texto proveniente de fuera de la semiosfera, este texto periférico se desplazó de nueva cuenta hacia la parte nuclear del sistema sígnico del Cholq’ij.

Pero tal retorno no fue completamente fiel a su estado anterior: la interacción con el nuevo contexto en el que circulaba información proveniente del exterior de su campo de significación tradicional (aquellos retomados del estudio de la cultura maya de otras latitudes y otras temporalidades diferentes a las k'iche') determinó que la concepción de Imox adquiriera nuevas características. El fácil acceso a otras fuentes - que aunque son de origen maya, debemos considerar como textos ajenos por no pertenecer en esos momentos a la oralidad propiaimpulsó el proceso creativo de los traductores que llevaron estos textos de la periferia al interior de la semiosfera, con las características propias que tiene en la actualidad, retomando y adecuando aquellos aspectos relevantes y comprensibles para la cultura actual, y desdeñando en cambio aquellos que no tenían relevancia trascendental. Surgió así un sentido eminentemente nuevo.

Entonces, hoy día, el nuevo texto sobre Imox aglutina esos contenidos que son significativos para los mayas contemporáneos que siguen usando la cuenta de 260 días como un sistema que los ayuda a interactuar con su mundo sagrado. Lo llamo "nuevo" porque este texto no representa una "cita textual" de las investigaciones en torno al calendario provenientes del medio académico: para los k'iche' y los grupos de Los Altos no es el nawal del monstruo terrestre, ni tampoco el primer día del calendario; es más, no existe la figura del Monstruo-lagarto en los mitos actuales como agente participante en la creación. En él vemos que se mantiene vigente el carácter "loco" que se le atribuyó por su relación con el lado izquierdo, y ahora ambos sentidos, lo acuático y lo alrevesado, se conjugan para dar como resultado toda una serie de características que los ajq’ijab le asignan en contextos rituales.

De este modo, Imox condensa por lo menos dos momentos de significación dentro de la semiosfera k'iche': por un lado, los aspectos caóticos, volubles, e incluso peligrosos reunidos en torno a la idea de su calidad siniestra relacionada con lo que se ubica a la izquierda (en oposición a lo diestro), y, por otro, los positivos, que giran en torno a su valencia hidrológica. 
El día-nawal Imox es una muestra de cómo se recuerdan y se recuperan los aspectos relevantes en la cultura. Estos textos se replantean a sí mismos como entes latentes y vigentes en un campo de significación cada vez más interactuante con la modernidad. 


\section{BIBLIOGRAFÍA}

Ajpacajá Tum, Pedro Florentino et al.

2005 Diccionario k'iche'. Guatemala: Proyecto Linguiístico Francisco Marroquín, Cholsamaj.

Arias Ortiz, Teri Erandeni

2004 "El cocodrilo en la cosmovisión maya: un proceso de larga duración", tesis de licenciatura en Etnohistoria. México: Escuela Nacional de Antropología e Historia.

Ayala Falcón, Maricela

1978 "El año de doscientos sesenta días", tesis de licenciatura en Historia. México: Universidad Nacional Autónoma de México, Facultad de Filosofía y Letras.

Barrera Vásquez, Alfredo et al.

1980 Diccionario maya-español. México: Cordemex.

Barrera Vásquez, Alfredo y Silvia Rendón

2005 El libro de los libros del Chilam Balam, traducción de sus textos paralelos por ..., basado en el estudio, cotejo y reconstrucción hechos por el primero, con introducciones y notas. México: Fondo de Cultura Económica (Colección Popular, 42).

Bastos Santiago, Aura Cumes y Leslie Lemus

2007 Mayanización y vida cotidiana. La ideología multicultural en la sociedad guatemalteca. Texto para debate. Guatemala: Facultad Latinoamericana de Ciencias Sociales, Centro de Investigaciones Regionales de Mesoamérica y Cholsamaj.

Brito Sansores, William

1981 La escritura de los mayas. México: Manuel Porrúa (Biblioteca Mexicana, 58).

Bunzel, Ruth Leah

1981 Chichicastenango, F. Gall (trad.). Guatemala: Editorial José de Pineda Ibarra y Ministerio de Educación.

Calendario Guatemala Maya

2005 Chichicastenango: Centro Cultural y Asistencia Maya (CCAM).

Caso, Alfonso

1967 Los calendarios prehispánicos. México: Universidad Nacional Autónoma de México, Instituto de Investigaciones Históricas (Serie de Cultura Náhuatl, Monografías, 6).

Calvin, Inga E.

2004 Maya hieroglyphics study guide. Fundación para el Avance de los Estudios Mesoamericanos, <www.famsi.org/mayawriting/calvin/index.html>.

Christenson, Allen J. (ed.)

2003 K'iche'-English dictionary and guide to pronunciation of the K'iche'-Maya alphabet. 
Fundación para el Avance de los Estudios Mesoamericanos, Brigham Young University, <www.famsi.org/mayawriting/dictionary/christenson/quidic complete.pdf $>$.

Cojtí Cuxil, Demetrio

1997 El movimiento maya en Guatemala. Guatemala: Cholsamaj.

De la Garza Camino, Mercedes

1988 El universo sagrado de la serpiente entre los mayas. México: Universidad Nacional Autónoma de México, Instituto de Investigaciones Filológicas, Centro de Estudios Mayas.

Esquit, Edgar

2002 Las rutas que nos ofrecen el pasado y el presente. Activismo político, historia y pueblo maya. Guatemala: Instituto de Estudios Interétnicos.

Estrada Peña, Canek

2010 "Ri Juyub', ri q'aq', ri nuch (El cerro, el fuego, el bebé): acerca de la presentación de un niño k'iche' ante el mundo", Estudios Mesoamericanos, Nueva Época, 9: 35-62.

2013 “Ideas del tiempo cíclico en la cuenta de 260 días entre los k’iche' contemporáneos. El ciclo ritual del día 8 B’atz' ”, Continuidad, cambios y rupturas en la religión maya, pp. 215-255, Mercedes de la Garza y María del Carmen Valverde (eds.). México: Universidad Nacional Autónoma de México, Instituto de Investigaciones Filológicas, Centro de Estudios Mayas.

Freidel, David, Linda Schele y Joy Parker

1999 El cosmos maya. Tres mil años por la senda de los chamanes. Jorge Ferreiro Santana (trad.). México: Fondo de Cultura Económica.

Gates, William Edmond

1978 An outline dictionary of maya glyphs, with a concordance and analysis of their

[1931] relationships. New York: Dover Publications Inc.

Goubaud Carrera, Antonio

1965 "Guajxaquip bats. Ceremonia calendárica indígena", Cuadernos de Antropología, 4: 7-18.

Guorón, Pedro, Lina Barrios y Audelino Sac Cocoy (comps.)

2002 Nuestra cultura maya. Pensamiento y vida maya. Guatemala: Editorial Saquil Tzij.

Historia de los mexicanos por sus pinturas

1965 Teogonía e historia de los mexicanos. Tres opúsculos del siglo XVI, pp. 21-90, Ángel Ma. Garibay K (ed.). México: Porrúa (Sepan cuantos..., 37).

Ixcot Pérez, Edgar Rolando

2004 Tzolkin. Calendario sagrado maya, presentación de J. E. Chuc Xum, introducción de D. Matul Morales. Guatemala: Editorial k'iche' Tzib', TIMACH, GTZ. 
Kettunen, Harri y Christophe Helmeke

2005 Introduction to Maya Hieroglyphs. Worshop Handbook. Leiden: Wayeb and Leiden University, <http://www.mesoweb.com/resources/handbook/WH2005. pdf $>$.

Kuxtab'al kan ke ri qati' qamam maya'iib. Memoria de los abuelos Maya Achi

2003 Guatemala: Asociación Ixoq Ajaaw.

Libro del Chilam Balam de Chumayel

2001 Antonio Mediz Bolio (trad.), Mercedes de la Garza (prol., introd. y n.). México: Consejo Nacional para la Cultura y las Artes (Cien de México).

Lincoln, J. Steward

1942 "The Maya Calendar of the Ixil of Guatemala", Contributions to American Anthropology and History, 38: 99-128.

López Austin, Alfredo

1996 "La cosmovisión mesoamericana", Temas Mesoamericanos, pp. 471-507, S. Lombardo y E. Nalda (coords.). México: Consejo Nacional para la Cultura y las Artes, Instituto Nacional de Antropología e Historia (Colección Obra Diversa).

2006 Los mitos del tlacuache. Caminos de la mitología mesoamericana, 4a ed. México: Universidad Nacional Autónoma de México, Instituto de Investigaciones Antropológicas.

Lotman, Iuri

1996 La semiosfera I. Semiótica de la cultura y del texto, vol 1. Madrid: Ediciones Cátedra, Universidad de Valencia, 3 vols.

Manual de interpretación del calendario sagrado maya

2002 Guatemala: Coordinadora Nacional Indígena Campesina (CONIC), Cosmovisión Indígena y Cultura Maya.

Morales Sic, José Roberto

2004 Religión y política: el proceso de institucionalización de la espiritualidad en el movimiento maya guatemalteco. Guatemala: Facultad Latinoamericana de Ciencias Sociales (Colección Cuadernos de Maestría).

Núñez de la Vega, Francisco

1988 Constituciones diocesanas del Obispado de Chiapa, María del Carmen León Cázares y Mario Humberto Ruz (eds.). México: Universidad Nacional Autónoma de México, Instituto de Investigaciones Filológicas, Centro de Estudios Mayas (Fuentes para el Estudio de la Cultura Maya, 6).

Pujb'il yol mam. Vocabulario Mam

2003b Guatemala: Academia de Lenguas Mayas de Guatemala, Comunidad Linguiística Mam, Dirección de Planificación Linguiística y Cultural, Subprograma de Estudios Linguiísticos. 
Relaciones Histórico-Geográficas de la Gobernación de Yucatán

1983 Mercedes de la Garza, Ana Luisa Izquierdo, María del Carmen León y Tolita Figueroa (eds.), María del Carmen León (paleogr.), vol I. México: Universidad Nacional Autónoma de México, Instituto de Investigaciones Filológicas, Centro de Estudios Mayas (Serie Fuentes para el Estudio de la Cultura Maya, 1).

Rupflin, Walburga

1999 El Tzolkin... es más que un calendario. Guatemala: Fundación Centro de Documentación Maya.

Saler, Benson

1969 Nagual, brujo y hechicero en un pueblo quiché. Guatemala: Editorial José de Pineda Ibarra, Ministerio de Educación (Cuadernos del Seminario de Integración Social de Guatemala, 20).

Schultze- Jena, Leonhard

1946 La vida y las creencias de los indígenas quichés de Guatemala, Antonio Goubaud Carrera y Herbert D. Sapper (trads.). Guatemala: Ministerio de Educación Pública.

Sotelo Santos, Laura Elena

1988 Los mitos cosmogónicos de los mayas en el siglo XVI. México: Universidad Nacional Autónoma de México, Instituto de Investigaciones Filológicas, Centro de Estudios Mayas (Serie Cuadernos, 19).

Spaxti'al Slolonelal. Vocabulario Chuj

2003 Guatemala: Academia de Lenguas Mayas de Guatemala, Comunidad Linguiística Chuj, Dirección de Planificación Linguiística y Cultural, Subprograma de Estudios Linguísticos.

Stuart, David

2010 Comentarios sobre las inscripciones del Templo XIX de Palenque, J. Pérez de Lara (trad.). San Francisco: The Pre-Columbian Art Research Institute, Precolumbian Mesoweb Press, <www.mesoweb.com/es/publicaciones/Stuart/TXIX.pdf>.

Tedlock, Bárbara

2002 El tiempo y los mayas del Altiplano. California: Fundación Yaxté.

Thompson, J. Eric S.

1960 Maya hieroglyphic writing. An introduction, 2a ed. Norman: University of [1950] Oklahoma Press.

Usemos nuestro calendario maya

2001 Guatemala: Academia de Lenguas Mayas de Guatemala, Dirección Linguiística y Cultural, Programa de Estudios Culturales.

Vargas Pacheco, Ernesto y Teri Arias Ortiz

2005 "El cocodrilo y el cosmos: Itzamkanac, el lugar de la casa del lagarto", XVIII 
Simposio de Investigaciones Arqueológicas en Guatemala, 2004, pp. 14-26, Juan Pedro Laporte, Bárbara Arroyo y Héctor Mejía (eds.). Guatemala: Museo Nacional de Arqueología y Etnología.

Velásquez García, Erik

2006 "El mito maya del diluvio y la decapitación del caimán cósmico", traducción de "The Maya Flood Myth and the Decapitation of the Cosmic Caiman", PARI Journal, 7 (1): 1-10, <www.mesoweb.com/pari/publications/journal/701/ Diluvio.pdf $>$.

Villa Rojas, Alfonso

2003 "Apéndice I. Los conceptos de espacio y tiempo entre los grupos mayances

[1968] contemporáneos", Tiempo y realidad en el pensamiento maya. Ensayo de acercamiento, 4a ed., pp. 123-168, Miguel León Portilla (ed.), Erick S. Thompson (pról.). México: Universidad Nacional Autónoma de México, Instituto de Investigaciones Históricas (Serie Culturas Mesoamericanas, 2).

Yool Gómez, Juan y Leonardo Sanahí Curruchich

1999 Acercamiento a la interpretación del Cholq’ij. Chimaltenango: KEMATZIJ, Centro de Desarrollo y Ciencia Maya.

Zapil Xivir, Juan

2007 "Aproximación linguiística y cultural a los 20 nawales del calendario maya practicado en Momostenango, Totonicapán", tesis de licenciatura en Linguiística. Guatemala: Universidad Rafael Landívar, Facultad de Humanidades. 